\title{
Efficacy of robot-assisted radical cystectomy (RARC) in advanced bladder cancer: results from the International Radical Cystectomy Consortium (IRCC)
}

\begin{abstract}
Ali Al-Daghmin', Eric C. Kauffman', Yi Shi', Ketan Badani², M. Derya Balbay ${ }^{3}$, Erdem Canda ${ }^{4}$, Prokar Dasgupta 5 ,6, Reza Ghavamian7, Robert Grubb III8, Ashok Hemal9, Jihad Kaouk ${ }^{10}$, Adam S. Kibel ${ }^{8}$, Thomas Maatman' ${ }^{11}$, Mani Menon ${ }^{12}$, Alex Mottrie ${ }^{13}$, Kenneth Nepple ${ }^{8}$, John G. Pattaras ${ }^{14}$, James O. Peabody ${ }^{12}$, Vassilis Poulakis ${ }^{15}$, Raj Pruthi ${ }^{16}$, Juan Palou Redorta ${ }^{17}$, Koon-Ho Rha ${ }^{18}$, Lee Richstone ${ }^{19}$, Francis Schanne ${ }^{20}$, Douglas S. Scherr ${ }^{21}$, Stefan Siemer ${ }^{22}$, Michael Stöckle ${ }^{22}$, Eric M. Wallen ${ }^{16}$, Alon Weizer ${ }^{23}$, Peter Wiklund ${ }^{24}$, Timothy Wilson ${ }^{25}$, Gregory Wilding', Michael Woods ${ }^{26}$ and Khurshid A. Guru'

${ }^{1}$ Roswell Park Cancer Institute, Buffalo, ${ }^{2}$ Columbia University Medical Center, New York, NY, USA, ${ }^{3}$ Memorial Sisli Hospital, Istanbul, ${ }^{4}$ Ankara Ataturk Training and Research Hospital, Ankara, Turkey, ${ }^{5}$ MRC Centre for Transplantation, King's College London, ${ }^{6}$ Department of Urology, Guy's Hospital, London, UK, ${ }^{7}$ Montefiore Medical Center, UN Hospital Albert Einstein College of Medicine, Bronx, NY, ${ }^{8}$ Washington University School of Medicine, St. Louis, MO, ${ }^{9}$ Wake Forest University Baptist Medical Center, Salem, NC, ${ }^{10} \mathrm{Cleveland}$ Clinic, Cleveland, OH, ${ }^{17}$ Michigan Urological Clinic, Grand Rapids, MI, ${ }^{12}$ Henry Ford Health System, Detroit, MI, USA, ${ }^{13}$ Onze-Lieve-Vrouw Ziekenhuis, Aalst, Belgium, ${ }^{14}$ Emory University School of Medicine, Atlanta, GA, USA, ${ }^{15}$ Doctor's Hospital of Athens, Athens, Greece, ${ }^{16}$ University of North Carolina, Wilmington, NC, USA, ${ }^{17}$ Fundacio Puigvert, Barcelona, Spain, ${ }^{18}$ Yonsei University Health Systems Severance Hospital, Seoul, Korea, ${ }^{19}$ Arthur Smith Institute for Urology, Long Island, NY, ${ }^{20}$ Urologic Surgical Associates of Delaware, Newark, $D E,{ }^{21}$ Samsung Medical College, New York, NY, USA, ${ }^{22}$ University Clinics of Saarland, Homburg, Germany, ${ }^{23}$ University of Michigan Health System, Ann Arbor, MI, USA, ${ }^{24}$ Karolinska University Hospital, Stockholm, Sweden, ${ }^{25}$ City of Hope and Beckman Research Institute, Duarte, CA, and ${ }^{26}$ Loyola University Medical Center, Maywood, IL, USA
\end{abstract}

\section{Objective}

To characterise the surgical feasibility and outcomes of robot-assisted radical cystectomy (RARC) for pathological T4 bladder cancer.

\section{Patients and Methods}

Retrospective evaluation of a prospectively maintained International Radical Cystectomy Consortium database was conducted for 1118 patients who underwent RARC between 2003 and 2012.

We dichotomised patients based on pathological stage $(\leq \mathrm{pT} 3$ vs pT4) and evaluated demographic, operative and pathological variables in relation to morbidity and mortality.

\section{Results}

In all, $1000 \leq$ pT3 and 118 pT4 patients were evaluated. The pT4 patients were older than the $\leq$ pT3 patients $(P=0.001)$.

The median operating time and blood loss were $386 \mathrm{~min}$ and $350 \mathrm{~mL}$ vs $396 \mathrm{~min}$ and $350 \mathrm{~mL}$ for $\mathrm{p} \mathrm{T} 4$ and $\leq \mathrm{pT} 3$, respectively.
The complication rate was similar ( $54 \%$ vs $58 \%$; $P=0.64$ ) among $\leq$ pT3 and pT4 patients, respectively. The overall 30 and 90 -day mortality rate was $0.4 \%$ and $1.8 \%$ vs $4.2 \%$ and $8.5 \%$ for $\leq$ pT3 vs pT4 patients $(P<0.001)$, respectively.

The body mass index (BMI), American Society of Anesthesiology score, length of hospital stay (LOS) >10 days, and 90-day readmission were significantly associated with complications in pT4 patients.

Meanwhile, BMI, LOS $>10$ days, grade 3-5 complications, 90-day readmission, smoking, previous abdominal surgery and neoadjuvant chemotherapy were significantly associated with mortality in pT4 patients. On multivariate analysis, BMI was an independent predictor of complications in pT4 patients, but not for mortality.

\section{Conclusions}

RARC for pT4 bladder cancer is surgically feasible but entails significant morbidity and mortality.

BMI was independent predictor of complications in pT4 patients. 


\section{Keywords}

IRCC, robot-assisted, radical cystectomy, bladder cancer, efficacy

\section{Introduction}

Although radical cystectomy (RC) and pelvic lymph node (LN) dissection is well established as the 'gold-standard' treatment for muscle-invasive and high-risk non-muscleinvasive bladder cancer [1], the management of locally advanced bladder cancer continues to be controversial. In the absence of local treatment, locally advanced bladder cancer can lead to adverse pelvic and urinary symptomology, in addition to disease progression, and such local symptoms significantly decreases patient quality of life [2]. Accordingly, it has been suggested that patients with locally advanced bladder cancer may benefit from $\mathrm{RC}$ as a palliative procedure or as part of a multimodality attempt towards curative intent $[3,4]$. However, due to significant reported morbidity and mortality of open RC in the setting of locally advanced bladder cancer, local extirpation has been questioned [5].

Robot-assisted RC (RARC) has emerged as an alternative approach to open RC based on an improved profile in terms of blood loss, transfusion rate, need for postoperative analgesia, recovery of bowel function, and length of hospital stay (LOS) [6-8]. Prior to the present study, the application of a robot-assisted approach to locally advanced bladder cancer has not been appropriately assessed due to previous selection bias for low-volume and LN-negative disease. It has been questioned whether the robot-assisted approach may lead to inferior outcomes in this setting due to a lack of tactile sensation, which may aid in avoiding positive surgical margins and in achieving complete resection. We sought to characterise the feasibility and surgical outcomes of RARC for pathological T4 bladder cancer.

\section{Patients and Methods}

A retrospective analysis of the prospectively maintained database of the International Robotic Cystectomy Consortium (IRCC), a collaborative effort of over 20 institutions comprising $\approx 1300$ patients treated with RARC for bladder cancer, was performed. We dichotomised patients based on pathological tumour stage into patients with $\leq$ pT3 and pT4 tumours.

Specific clinical and pathological data was collected and analysed for patients which included: demographic variables (age, gender, body mass index [BMI], American Society of Anesthesiology [ASA] score, and smoking), preoperative disease characteristics (preoperative chemotherapy, abdominal surgery, and radiation), operative variables (estimated blood loss [EBL], LOS, length of intensive care unit (ICU) stay, type of diversion, and technique of diversion; intracorporeal vs extracorporeal), pathological characteristics (tumour stage, LN yield, and number of positive LNs), and 90-day postoperative outcomes (complications, readmission and mortality).

Patient comorbidity was assessed preoperatively using the ASA score. Complications were identified, defined and classified using the modified Clavien system [9]. The technique of RARC and pelvic LN dissection varied according to the individual surgeon and institution. Urinary diversion was performed both by intracorporeal and extracorporeal techniques.

Descriptive statistics, such as frequencies and relative frequencies, were computed for all categorical outcomes. Numeric outcomes were summarised using summary statistics such as the mean, standard deviation (SD), range, etc. Associations between baseline characteristics and pathological stage were statistically assessed using Fisher's exact test for categorical outcomes, and Wilcoxon rank-sum test for continuous outcomes. Univariate and multivariate logistic regression models were fit to evaluate preoperative, operative and postoperative predictors of readmission, complication and mortality. All statistical analysis was performed using SAS software (version 9.3, SAS Institute Inc., Cary, NC, USA). All tests were two-side, with statistical significance defined as $P<0.05$.

\section{Results}

In all, $1000 \leq \mathrm{pT} 3$ and $118 \mathrm{pT} 4$ patients were analysed. The pT4 patients were older than the $\leq$ pT3 patients, at a mean of 70 and 67 years, respectively $(P=0.001)$. Both groups were comparable for gender, ASA score, rates of prior abdominal surgery or neoadjuvant chemotherapy, LOS, EBL and operating time. The intraoperative blood transfusion rate was significantly higher among pT4 patients compared with $\leq$ pT3 patients, at $12 \%$ vs $4 \%$, respectively $(P=0.049)$.

There were statistically significant differences between $\leq \mathrm{pT} 3$ and pT4 patients for BMI (27.8 and $26.3 \mathrm{~kg} / \mathrm{m}^{2}$, respectively; $P=0.008)$, and salvage cystectomy after radiation $(1.4 \%$ and $5.9 \%$, respectively; $P<0.001$ ).

The mean number of LNs removed was not significantly different between $\leq \mathrm{pT} 3$ and pT4 patients (19.2 vs 17.3, respectively; $P=0.145$ ); however, more pT4 patients had positive LNs ( $55 \%$ vs $23 \%$; $P<0.001$ ). The rate of positive surgical margin at cystectomy was $4 \%$ and $31.5 \%(P=0.001)$ for $\leq$ pT3 and pT4 patient, respectively.

The mean follow-up time for $\mathrm{pT} 4$ and $\leq \mathrm{pT} 3$ patients was 10.6 and 17 months, respectively $(P<0.001)$. The pT4 patients underwent ileal conduit more often than the $\leq$ pT 3 patients ( $87 \%$ vs $66 \% ; P<0.001$ ). The length of ICU stay was 1 day 
Table 1 Patient demographics.

\begin{tabular}{|c|c|c|c|}
\hline & Pathological stage $\leq 3$ & Pathological stage 4 & $\boldsymbol{P}$ \\
\hline \multicolumn{4}{|l|}{ Preoperative characteristics } \\
\hline Overall number of patients & 1000 & 118 & \\
\hline Age, years & & & 0.001 \\
\hline mean (SD) & $67(0.4)$ & $70(0.9)$ & \\
\hline median (range) & $68.0(26-90)$ & $72.0(28-90)$ & \\
\hline Male gender, \% & 80 & 76 & 0.40 \\
\hline \multicolumn{4}{|l|}{$\mathrm{BMI}, \mathrm{kg} / \mathrm{m}^{2}:$} \\
\hline mean $(\mathrm{SD})$ & $27.8(0.2)$ & $26.3(0.5)$ & 0.01 \\
\hline Obese $\left(>30 \mathrm{~kg} / \mathrm{m}^{2}\right), n(\%)$ & $78(9)$ & $9(8)$ & 0.90 \\
\hline ASA score $\geq 3, n(\%)$ & $578(58)$ & $77(66)$ & 0.12 \\
\hline Neoadjuvant chemotherapy, $n(\%)$ & $139(14)$ & $17(14)$ & 0.90 \\
\hline Clinical stage, $n(\%)$ & & & $<0.001$ \\
\hline$\leq \mathrm{T} 2$ & $673(93)$ & $63(76)$ & \\
\hline$>\mathrm{T} 2$ & $52(7)$ & $20(24)$ & \\
\hline Preoperative radiation, $n$ (\%) & $14(1.4)$ & $7(5.9)$ & $<0.001$ \\
\hline Prior abdominal surgery, $n(\%)$ & $421(42)$ & $46(39)$ & 0.52 \\
\hline Diversion type, $n(\%)$ : & & & $<0.001$ \\
\hline ileal conduit & $659(66)$ & $103(87)$ & \\
\hline continent & $341(34)$ & $15(13)$ & \\
\hline Diversion location, $n(\%)$ : & & & 0.625 \\
\hline intracorporeal & $755(76)$ & $94(80)$ & \\
\hline extracorporeal & $208(21)$ & $22(19)$ & \\
\hline \multicolumn{4}{|l|}{ Pathological outcomes } \\
\hline Positive surgical margins, $n$ (\%) & $43(4.4)$ & $34(31.5)$ & $<0.001$ \\
\hline LN positive, $n(\%)$ & $228(23)$ & $65(55)$ & $<0.001$ \\
\hline LN yield: & & & 0.15 \\
\hline mean (SD) & $19.2(0.4)$ & $17.3(1.1)$ & \\
\hline median (range) & $18(0.0-74.0)$ & $17(0.0-54.0)$ & \\
\hline Follow-up, months: & & & $<0.001$ \\
\hline mean $(\mathrm{SD})$ & $17.0(0.6)$ & $10.6(1.2)$ & \\
\hline median (range) & $11(0.0-85.0)$ & $6(0.0-61)$ & \\
\hline \multicolumn{4}{|l|}{ Perioperative outcomes } \\
\hline Overall operating time, min & & & 0.47 \\
\hline mean $(\mathrm{SD})$ & $406.0(3.9)$ & $394.6(9.6)$ & \\
\hline median (range) & $396(50.0-862)$ & $386(0.0-618)$ & \\
\hline $\mathrm{EBL}, \mathrm{mL}:$ & & & 0.47 \\
\hline mean (SD) & $450.9(12.1)$ & $522.8(51.5)$ & \\
\hline median (IQR) & $350.0(0.0-3900)$ & $350.0(0.0-3700)$ & \\
\hline Intraoperative transfusion, $n(\%)$ & $10(4.0)$ & $4(11.8)$ & 0.049 \\
\hline ICU stay, days: & & & $<0.001$ \\
\hline mean (SD) & $1.0(0.1)$ & $1.8(0.4)$ & \\
\hline median (IQR) & $0.0(0-36)$ & $1.0(0-21)$ & \\
\hline Hospital stay, days: & & & 0.84 \\
\hline mean $(\mathrm{SD})$ & $11.1(0.3)$ & $11.1(0.7)$ & \\
\hline median (IQR) & $9.0(0-78)$ & $9.0(1-57)$ & \\
\hline Complications, $n$ (\%) & & & 0.64 \\
\hline Clavien 1-2 & $349(35)$ & $45(38)$ & \\
\hline Clavien 3-5 & $190(19)$ & $24(20)$ & \\
\hline Readmission, $n$ (\%) & & & 0.32 \\
\hline 30 days & $114(11)$ & $9(8)$ & \\
\hline 90 days & $174(17.4)$ & $23(19.5)$ & \\
\hline Mortality, $n$ (\%) & & & $<0.001$ \\
\hline 30 days & $4(0.4)$ & $5(4.2)$ & \\
\hline 90 days & $18(1.8)$ & $10(8.5)$ & \\
\hline
\end{tabular}

and 1.8 days for $\leq$ pT3 and pT4 patient, respectively $(P<$ $0.001)$. The complication rate was similar between $\leq \mathrm{pT} 3$ and pT4 patients (54\% vs $58 \%$ ) with $19.0 \%$ and $20 \%$ of the complications being Clavien grade $\geq 3$, respectively. The 90 -day readmission was similar. The overall 30 - and 90-day mortality rate was $0.4 \%$ and $1.8 \%$ vs $4.2 \%$ and $8.5 \%$ for $\leq \mathrm{pT} 3$ and pT4 patients, respectively $(P<0.001$; Table 1$)$.
On univariate analysis, BMI, ASA score, LOS $>10$ days, and 90-day readmission were significantly associated with complications in pT4 patients (Table 2). However, on multivariate analysis, only BMI was an independent predictor of complications in pT4 patients (Table 2). Meanwhile, on univariate analysis BMI, LOS $>10$ days, Clavien grade 3-5 complications, 90-day readmission, smoking, previous 
Table 2 Univariable and multivariable logistic regression analysis to evaluate variables associated with 90-day complications.

\begin{tabular}{|c|c|c|}
\hline \multirow[t]{2}{*}{ Variable } & \multicolumn{2}{|c|}{ 90-Day complications } \\
\hline & OR $(95 \% \mathrm{CI})$ & $\boldsymbol{P}$ \\
\hline \multicolumn{3}{|l|}{ Preoperative variables - univariable analysis } \\
\hline Gender (female vs male) & $1.0(0.43-2.34)$ & 1.000 \\
\hline Age at surgery (10-year interval) & $1.1(0.72-1.58)$ & 0.744 \\
\hline BMI $\left(\mathrm{kg} / \mathrm{m}^{2}\right)$ & $1.1(1.04-1.22)$ & 0.005 \\
\hline Obese (BMI $>30 \mathrm{~kg} / \mathrm{m}^{2}$, yes $/ \mathrm{no}$ ) & $8.0(0.97-66.34)$ & 0.054 \\
\hline Preoperative chemotherapy (yes/no) & $1.2(0.41-3.22)$ & 0.79 \\
\hline Current smoker (yes/no) & $2.42(0.98-5.98)$ & 0.06 \\
\hline ASA 3-4 vs $1-2$ & $0.50(0.23-1.09)$ & 0.08 \\
\hline \multicolumn{3}{|l|}{ Preoperative variables - multivariable analysis } \\
\hline Gender (male vs female) & $1.30(0.43-3.92)$ & 0.65 \\
\hline Age at surgery (10-year interval) & $1.20(0.72-1.99)$ & 0.49 \\
\hline BMI $\left(\mathrm{kg} / \mathrm{m}^{2}\right)$ & $1.12(1.02-1.22)$ & 0.02 \\
\hline Current smoker (yes/no) & $2.90(0.98-8.68)$ & 0.06 \\
\hline ASA $(1-2$ vs $3-4)$ & $0.34(0.12-1.02)$ & 0.05 \\
\hline Preoperative chemotherapy (yes/no) & $0.90(0.25-3.10)$ & 0.85 \\
\hline \multicolumn{3}{|l|}{ Intraoperative variables - univariable analysis } \\
\hline Operating room time ( $\leq 6$ vs $>6 \mathrm{~h}$ ) & $0.58(0.27-1.25)$ & 0.16 \\
\hline EBL $(\leq 800$ vs $>800 \mathrm{~mL})$ & $3.0(0.90-10.10)$ & 0.08 \\
\hline Type of urinary diversion (continent vs conduit) & $0.63(0.21-1.90)$ & 0.41 \\
\hline Location of diversion (intra vs extracorporeal) & $2.50(0.95-6.80)$ & 0.03 \\
\hline \multicolumn{3}{|l|}{ Intraoperative variables - multivariable analysis } \\
\hline Operating room time ( $\leq 6 \mathrm{vs}>6 \mathrm{~h})$ & $0.58(0.26-1.30)$ & 0.19 \\
\hline EBL $(\leq 800$ vs $>800 \mathrm{~mL})$ & $3.26(0.93-11.40)$ & 0.06 \\
\hline Type of urinary diversion (continent vs conduit) & $2.69(0.93-7.77)$ & 0.06 \\
\hline \multicolumn{3}{|l|}{ Postoperative variables - univariable analysis } \\
\hline Hospital stay ( $<10$ vs $\geq 10$ days $)$ & $2.14(1.00-4.56)$ & 0.047 \\
\hline ICU stay & $1.15(0.94-1.42)$ & 0.18 \\
\hline 90-day readmission & $32.35(4.17-250.87)$ & 0.0009 \\
\hline \multicolumn{3}{|l|}{ Postoperative variables - multivariable analysis } \\
\hline Hospital stay ( $<10$ vs $\geq 10$ days $)$ & $1.49(0.60-3.80)$ & 0.40 \\
\hline ICU stay & $1.13(0.92-1.40)$ & 0.24 \\
\hline
\end{tabular}

abdominal surgery, ileal conduit diversion and neoadjuvant chemotherapy were significantly associated with overall mortality in pT4 patients. On multivariate analysis, BMI was an independent predictor of complications in pT4 patients, but not an independent predictor for mortality (Tables 2,3).

\section{Discussion}

To date, only small case series have been reported regarding RC in pT4 bladder cancer, and data about cancer outcomes are sparse, and no reports specifically address efficiency of RARC in locally advanced bladder cancer $[10,11]$.

Long-term survival is dismal when bladder cancer invades the pelvic sidewall or adjacent structures, yet RC can provide palliation and accurate staging [12]. The rationale behind advocating RC in locally advanced disease could be explained by increasing evidence supporting meticulous surgical clearance with extended lymphadenectomy both of which can significantly impact disease-free survival [13]. Hence, 'debulking' surgery may have oncological benefit in bladder cancer, as is well established in other malignancies, e.g. ovarian cancer. In the randomised Southwest Oncology Group (SWOG) trial in which neoadjuvant chemotherapy followed
Table 3 Univariable and multivariable logistic regression analysis to evaluate variables associated with 90-day mortality.

\begin{tabular}{|c|c|c|}
\hline \multirow[t]{2}{*}{ Variable } & \multicolumn{2}{|c|}{ 90-Day mortality } \\
\hline & OR $(95 \% \mathrm{Cl})$ & $\mathbf{P}$ \\
\hline \multicolumn{3}{|l|}{ Preoperative variables - univariable analysis } \\
\hline Gender (female vs male) & $0.98(0.41-2.34)$ & 0.96 \\
\hline Age at surgery (10-year interval) & $1.04(0.70-1.55)$ & 0.85 \\
\hline $\operatorname{BMI}\left(\mathrm{kg} / \mathrm{m}^{2}\right)$ & $1.10(1.02-1.20)$ & 0.013 \\
\hline Obese (BMI $>30 \mathrm{~kg} / \mathrm{m}^{2}$, yes $\left./ \mathrm{no}\right)$ & $3.40(0.80-14.43)$ & 0.096 \\
\hline Preoperative chemotherapy (yes/no) & $3.35(1.14-9.84)$ & 0.028 \\
\hline Current smoker (yes/no) & $3.29(1.23-8.80)$ & 0.018 \\
\hline ASA 3-4 vs1-2 & $1.69(0.76-3.78)$ & 0.20 \\
\hline Prior abdominal surgery & $2.38(1.10-5.13)$ & 0.027 \\
\hline \multicolumn{3}{|l|}{ Preoperative variables - multivariable analysis } \\
\hline Gender (male vs female) & $1.20(0.42-3.46)$ & 0.76 \\
\hline Age at surgery (10-year interval) & $1.09(0.65-1.82)$ & 0.75 \\
\hline BMI $\left(\mathrm{kg} / \mathrm{m}^{2}\right)$ & $1.07(0.99-1.16)$ & 0.11 \\
\hline Current smoker (yes/no) & $2.69(0.90-8.10)$ & 0.08 \\
\hline ASA (1-2 vs $3-4)$ & $1.16(0.44-3.10)$ & 0.77 \\
\hline Preoperative chemotherapy (yes/no) & $2.32(0.69-7.71)$ & 0.17 \\
\hline \multicolumn{3}{|l|}{ Intraoperative variables - univariable analysis } \\
\hline Operating room time ( $\leq 6$ vs $>6 \mathrm{~h}$ ) & $0.70(0.32-1.54)$ & 0.38 \\
\hline $\mathrm{EBL}(\leq 800$ vs $>800 \mathrm{~mL})$ & $1.82(0.61-5.45)$ & 0.29 \\
\hline Type of urinary diversion (continent vs conduit) & $0.20(0.04-0.93)$ & 0.04 \\
\hline Location of diversion (intra vs extracorporeal) & $1.30(0.53-3.423)$ & 0.54 \\
\hline \multicolumn{3}{|l|}{ Intraoperative variables - multivariable analysis } \\
\hline Operating room time ( $\leq 6 \mathrm{vs}>6 \mathrm{~h})$ & $0.63(0.28-1.43)$ & 0.27 \\
\hline $\mathrm{EBL}(\leq 800 \mathrm{vs}>800 \mathrm{~mL})$ & $2.19(0.70-6.77)$ & 0.17 \\
\hline Type of urinary diversion (continent vs conduit) & $1.38(0.52-3.68)$ & 0.52 \\
\hline \multicolumn{3}{|l|}{ Postoperative variables - univariable analysis } \\
\hline Hospital stay ( $<10$ vs $\geq 10$ days) & $2.60(1.20-5.60)$ & 0.015 \\
\hline ICU stay & $1.10(0.95-1.27)$ & 0.19 \\
\hline 90-day readmission & $3.39(1.29-8.92)$ & 0.013 \\
\hline \multicolumn{3}{|l|}{ Complications } \\
\hline Clavien 0 vs $3-5$ & $0.15(0.049-0.45)$ & 0.0007 \\
\hline Clavien $1-2$ vs Clavien $3-5$ & $0.67(0.24-1.87)$ & 0.45 \\
\hline \multicolumn{3}{|l|}{ Postoperative variables - multivariable analysis } \\
\hline Hospital stay ( $<10 \mathrm{vs} \geq 10$ days) & $1.22(0.47-3.14)$ & 0.66 \\
\hline ICU stay & $1.10(0.92-1.25)$ & 0.40 \\
\hline \multicolumn{3}{|l|}{ Complications } \\
\hline Clavien 0 vs $3-5$ & $0.11(0.01-1.47)$ & 0.10 \\
\hline Clavien $1-2$ vs Clavien 3-5 & $0.74(0.23-2.33)$ & 0.25 \\
\hline
\end{tabular}

by RC compared with RC alone showed a survival benefits in patients who received neoadjuvant chemotherapy with T2 disease (105 vs 75 months; $P=0.05$ ) and for T3 or T4a disease (65 vs 24 months; $P=0.05$ ) [3]. The data for adjuvant chemotherapy are less compelling. However, benefits may be derived for patients who progress to extensive disease [14,15]. Neoadjuvant chemotherapy was administered to $14.4 \%$ patients in present cohort, despite proved efficacy.

The present outcomes show that operating time, EBL and LOS were comparable between $\mathrm{pT} 4$ and $\leq \mathrm{pT} 3$ patients. These findings support similar observations by Hayn et al. [16] who reported an EBL of $400 \mathrm{~mL}$, operating time of $6.3 \mathrm{~h}$ and LOS of 8 days. The present overall 90-day complication rate was not higher among pT4 patients; however, 90-day mortality was. The present complication rates were similar to those in previously published RARC series, although the high-grade complications were higher [7,8]. Pruthi et al. [17] reported major surgical complications (Clavien grade $\geq 3$ ) in $8 \%$ of their 
patients, with $13 \%$ of patients having non-organ-confined disease. Higher mortality and high-grade complications in the present series could be explained by the advanced nature of the disease in our series, which has not been addressed in RARC literature and the multi-institutional nature of our series, which represent variation in operative expertise, patient selection, and quality of perioperative care. In the present study, there was no difference in 90 -day readmission between $\leq$ pT3 and pT4 patients. Stimson et al. [18] reported a 90-day readmission rate of $26.6 \%$, which was slightly higher than our present pT4 patients (19.5\%) for the same period.

In a study by Nagele et al. [10], 20 patients underwent RC for locally advanced bladder cancer (T4a/b), the LOS was 19 days, $50 \%$ of patients received an intraoperative blood transfusion and $50 \%$ died within a mean (range) interval of 7 (2-19) months. Furthermore, Hemal et al. [11] evaluated the feasibility of laparoscopic RC for loco-regionally advanced bladder cancer in 13 patients and reported a $57 \%$ blood transfusion rate, LOS was 11 days, and there was one mortality at $\leq 30$ days.

In all, $45 \%$ of patients with pT4 disease in the present study underwent a LN dissection with negative LNs and a mean LN yield of 17, similar to Tilki et al. [19] who reported 54\% incidence of LN metastasis in pT4 bladder cancer. The impact of LN metastasis on survival after RC was reported by Shariat et al. [20] who found that in patients with non-organ-confined and LN-negative disease the progression-free survival (PFS) and cancer-specific survival (CSS) were $55 \%$ and $59 \%$, respectively, compared with patients with LN metastasis, where PFS and CSS were only $29 \%$ and $37 \%$, respectively.

Local cancer control in terms of total resection is an important predictor of survival in patients with pT4, as patients with positive margins are significantly more likely to have disease recurrence, as demonstrated by Dotan et al. [21] . In the present study, $31.5 \%$ of pT4 patients had positive margins compared with $24 \%$ reported in an open RC series by Novara et al. [22] and $25 \%$ by Tilki et al. [19]. Due to limitation of data, sites of positive margins could not be defined.

One of the primary aims of the present study was to identify predictors of complications and mortality in pT4 patients after RARC. BMI was the only independent predictor of complications. Reyes et al. [23] reported a higher incidence of infection-related complications in patients with higher BMI. Kouba et al. [24] found more stomal complications after RC and ileal conduit diversion in obese patients. In contrast, Poch et al. [25] found that RARC and intracorporeal ileal conduit was feasible for overweight and obese patients compared with patients with normal BMI, and other investigators have found no association between BMI and complications after RC, including RARC [26].
The present study has its limitations. First, the limitations inherent to retrospective analysis. Given the large number of surgeons and their variability, selection and reporting bias might have influenced the results. Second, most surgeons in the IRCC had previous experience in robot-assisted surgery. Thus, results might not be applicable to all urological surgeons. Third, the number of patients varied widely among the institutions. Thus, the overall outcomes might have been influenced by data from the institutions with greater experience. It is crucial to consider the economic impact of robot use to fully evaluate this approach; however, the present data are lacking regarding the cost. Finally, we did not have prospective data on outcomes for functional status and quality of life outcomes. Additional follow-up is needed to assess any long-term oncological or survival outcomes.

In conclusion, RARC for locally advanced bladder cancer is surgically feasible with significant morbidity and mortality. BMI was found to be an independent predictor of complications in pT4 patients.

\section{Conflict of Interest}

K.A.G. reports funding from Simulated Surgical Systems, outside the submitted work; and as a Board Member with Simulated Surgical Systems.

All other authors have nothing to disclose.

\section{References}

1 Stenzl A, Cowan NC, De Santis M et al. Treatment of muscle-invasive and metastatic bladder cancer: update of the EAU guidelines. Eur Urol 2011; 59: 1009-18

2 Lodde M, Palermo S, Comploj E et al. Four years experience in bladder preserving management for muscle invasive bladder cancer. Eur Urol 2005; 47: 773-9

3 Grossman HB, Natale RB, Tangen CM et al. Neoadjuvant chemotherapy plus cystectomy compared with cystectomy alone for locally advanced bladder cancer. N Engl J Med 2003; 349: 859-66

4 Power NE, Kassouf W, Bell D et al. Natural history of pT3-4 or node positive bladder cancer treated with radical cystectomy and neoadjuvant chemotherapy in a contemporary North-American multi-institutional cohort. Can Urol Assoc J 2012; 6: E217-23

5 Stein JP, Lieskovsky G, Cote R et al. Radical cystectomy in the treatment of invasive bladder cancer: long-term results in 1,054 patients. J Clin Oncol 2001; 19: 666-75

6 Wang GJ, Barocas DA, Raman JD, Scherr DS. Robotic vs open radical cystectomy: prospective comparison of perioperative outcomes and pathological measures of early oncological efficacy. BJU Int 2008; 101 : 89-93

7 Nix J, Smith A, Kurpad R, Nielsen ME, Wallen EM, Pruthi RS. Prospective randomized controlled trial of robotic versus open radical cystectomy for bladder cancer: perioperative and pathologic results. Eur Urol 2010; 57: 196-201

8 Guru KA, Wilding GE, Piacente $P$ et al. Robot-assisted radical cystectomy versus open radical cystectomy: assessment of postoperative pain. Can J Urol 2007; 14: 3753-6 
9 Dindo D, Demartines N, Clavien PA. Classification of surgical complications: a new proposal with evaluation in a cohort of 6336 patients and results of a survey. Ann Surg 2004; 240: 205-13

10 Nagele U, Anastasiadis AG, Merseburger AS et al. The rationale for radical cystectomy as primary therapy for T4 bladder cancer. World J Urol 2007; 25: 401-5

11 Hemal AK, Kolla SB, Wadhwa P. Evaluation of laparoscopic radical cystectomy for loco-regionally advanced bladder cancer. World J Urol 2008; 26: 161-6

12 Stewart BH, Novick AC. Current perspectives on palliative therapy in cancer of the bladder. Cancer Res 1977; 37: 2781-8

13 Konety BR, Joslyn SA, O'Donnell MA. Extent of pelvic lymphadenectomy and its impact on outcome in patients diagnosed with bladder cancer: analysis of data from the Surveillance, Epidemiology and End Results Program data base. J Urol 2003; 169: 946-50

14 Studer UE, Bacchi M, Biedermann C et al. Adjuvant cisplatin chemotherapy following cystectomy for bladder cancer: results of a prospective randomized trial. J Urol 1994; 152: 81-4

15 Lehmann J, Franzaring L, Thuroff J, Wellek S, Stockle M. Complete long-term survival data from a trial of adjuvant chemotherapy vs control after radical cystectomy for locally advanced bladder cancer. BJU Int 2006; 97: 42-7

16 Hayn MH, Hellenthal NJ, Hussain A, Stegemann AP, Guru KA. Defining morbidity of robot-assisted radical cystectomy using a standardized reporting methodology. Eur Urol 2011; 59: 213-8

17 Pruthi RS, Nielsen ME, Nix J, Smith A, Schultz H, Wallen EM. Robotic radical cystectomy for bladder cancer: surgical and pathological outcomes in 100 consecutive cases. J Urol 2010; 183: 510-4

18 Stimson CJ, Chang SS, Barocas DA et al. Early and late perioperative outcomes following radical cystectomy: 90 -day readmissions, morbidity and mortality in a contemporary series. J Urol 2010; 184: 1296-300

19 Tilki D, Svatek RS, Karakiewicz PI et al. Characteristics and outcomes of patients with pT4 urothelial carcinoma at radical cystectomy: a retrospective international study of 583 patients. J Urol 2010; 183: 87-93

20 Shariat SF, Karakiewicz PI, Palapattu GS et al. Outcomes of radical cystectomy for transitional cell carcinoma of the bladder: a contemporary series from the Bladder Cancer Research Consortium. J Urol 2006; 176 : $2414-22$
21 Dotan ZA, Kavanagh K, Yossepowitch O et al. Positive surgical margins in soft tissue following radical cystectomy for bladder cancer and cancer specific survival. J Urol 2007; 178: 2308-13

22 Novara G, Svatek RS, Karakiewicz PI et al. Soft tissue surgical margin status is a powerful predictor of outcomes after radical cystectomy: a multicenter study of more than 4,400 patients. J Urol 2010; 183: 2165-70

23 Reyes MA, Nieder AM, Kava BR, Soloway MS, Manoharan M. Does body mass index affect outcome after reconstruction of orthotopic neobladder? Urology 2007; 69: 475-8

24 Kouba E, Sands M, Lentz A, Wallen E, Pruthi RS. Incidence and risk factors of stomal complications in patients undergoing cystectomy with ileal conduit urinary diversion for bladder cancer. J Urol 2007; 178: 950-4

25 Poch MA, Stegemann A, Chandrasekhar R, Hayn M, Wilding G, Guru KA. Does body mass index impact the performance of robot-assisted intracorporeal ileal conduit? J Endourol 2012; 26: 857-60

26 Kauffman EC, Ng CK, Lee MM, Otto BJ, Wang GJ, Scherr DS. Early oncological outcomes for bladder urothelial carcinoma patients treated with robotic-assisted radical cystectomy. BJU Int 2011; 107: $628-35$

Correspondence: Khurshid A. Guru, MD, Robert P. Huben Professor of Urologic Oncology, Department of Urology, Roswell Park Cancer Institute, Elm and Carlton Streets, Buffalo, New York 14263, USA.

e-mail: khurshid.guru@roswellpark.org

Abbreviations: ASA, American Society of Anesthesiology score; CSS, cancer-specific survival; EBL, estimated blood loss; ICU, intensive care unit; IRCC, International Radical Cystectomy Consortium; LN, lymph node; LOS, length of hospital stay; PFS, progression-free survival; (RA)RC, (robot-assisted) radical cystectomy. 